\title{
Review: discontinuation rates are the same for serotonin specific reuptake inhibitors and newer tricyclic and heterocyclic antidepressants
}

Hotopf $M$, Hardy R, Lewis G. Discontinuation rates of SSRls and tricyclic antidepressants: a meta-analysis and investigation of heterogeneity. BrJ Psychiatry. $1997 \mathrm{Feb}$ 170:120-7.

\section{Objective}

To determine if the advantage in discontinuation rates of serotonin specific reuptake inhibitors (SSRIs) shown in previous reviews was present when compared with newer tricyclic or heterocyclic antidepressants for the treatment of depression.

\section{Data sources}

As part of an ongoing Cochrane Collaboration review, randomised controlled trials were identified by searching Medline for previous reviews that compared SSRIs (fluoxetine, sertraline, paroxetine, and fluvoxamine) with tricyclics and heterocyclics. Additional studies were identified by hand searching 2 journals. If data for discontinuation rates were not complete, the first author was contacted.

\section{Study selection}

Trials were selected if they compared tricyclics or heterocyclics with SSRIs for the treatment of depression. Studies of these compounds for other indications were excluded.

\section{Data extraction}

Data were extracted on discontinuation rates, type of SSRI used, type of tricyclic or heterocyclic used, patient numbers, and whether the treated patients were $\geqslant 60$ to 70 years of age.

\section{Main resultsKeywords: Keywords please}

Tricyclics and heterocyclics were classified into 1 of 3 groups: reference compounds (imipramine and amitriptyline); newer tricyclics (dothiepin, nortriptyline, desipramine, clomipramine, and doxepin); and heterocyclics (bupropion, mianserin, trazodone, maprotiline, amineptine, and nomifensine). Discontinua- tion rates were lower for SSRIs compared with tricyclics and heterocyclics combined $\{\mathrm{p}<0.01\}^{*}$ and compared with reference compounds $\{\mathrm{p}<0.05\}^{*}$ (table). No differences in discontinuation rates were found when SSRls were compared with either newer tricyclics (odds ratio [OR] $0.89,95 \%$ CI 0.74 to 1.06 ) or heterocyclics (OR 1.02, CI 0.78 to 1.35 ).

\section{Conclusions}

Rates of discontinuation are the same for SSRIs and newer tricyclic and heterocyclic antidepressants. The advantage of SSRIs shown in previous reviews is caused by the use of old tricyclics as reference compounds.

Serotonin specific reuptake inhibitors (SSRIs) v tricyclics and heterocyclics combined and reference drugst

\begin{tabular}{llclll}
\hline \multirow{2}{*}{ Outcomes } & $\begin{array}{l}\text { SSRIs } \\
\text { weighted }\end{array}$ & $\begin{array}{c}\text { Control } \\
\text { weighted }\end{array}$ & $\begin{array}{l}\text { RRR } \\
(95 \% \text { CI) }\end{array}$ & $\begin{array}{l}\text { Weighted } \\
\text { ARR }\end{array}$ & $\begin{array}{l}\text { NNT } \\
\text { (CI) }\end{array}$ \\
\hline $\begin{array}{c}\text { Discontinuation } \\
\text { (combined drugs) }\end{array}$ & $31 \%$ & $33 \%$ & $\begin{array}{l}8 \% \\
(3 \text { to } 14)\end{array}$ & $2.4 \%$ & $\begin{array}{l}42 \\
(24 \text { to } 148)\end{array}$ \\
$\begin{array}{c}\text { Discontinuation } \\
\text { (reference drugs) }\end{array}$ & $35 \%$ & $38 \%$ & $\begin{array}{l}10 \% \\
(3 \text { to } 16)\end{array}$ & $3.1 \%$ & $\begin{array}{l}32 \\
(19 \text { to } 139)\end{array}$ \\
\hline
\end{tabular}

$\uparrow$ Abbreviations defined in glossary; RRR, ARR, NNT, and CI calculated from data in article.

*p values calculated from data in article.

Source of funding:Medical Research Council Clinical Training Fellowship.

For article reprint: Dr M Hotopf, Department of Psychological Medicine, King's College School of Medicine and Dentistry and Institute of Psychiatry, 103 Denmark Hill, Londom SE 5 8AZ, UK.

Abstract and commentary also published in Evidence-Based Medicine 1997 Sep-Oct;2:149.

\section{Commentary}

The review by Hotopf $e t$ al is consistent with previous reviews that show that the dropout rate from treatment for depression with SSRIs, which is itself quite substantial at around 30\%, is only slightly lower than the dropout rate with tricyclic antidepressants. ${ }^{1-3}$ The relevance of the finding that this difference disappears when SSRIs are compared with "newer" tricyclics or heterocyclics is less clear. The distinction made between older and newer tricyclics is not well established, and other reviews categorise these drugs differently. ${ }^{2}{ }^{4}$ Evidence from general practice that tricyclics, with the exception of lofepramine, continue to be prescribed in "subtherapeutic" doses in most cases seems to suggest that these drugs are not well tolerated at recommended antidepres- sant doses. ${ }^{5}$ Further investigation is needed into the efficacy of low dose treatment with tricyclics because there is currently inadequate evidence about this issue.

Because tricyclics and SSRIs seem to be equally effective, the decision about which to use depends on balancing issues of tolerability, toxicity, and cost. ${ }^{3}{ }^{4}$ SSRIs are clearly less dangerous in overdose, although the tricyclic lofepramine has a similar advantage. Cost favours tricyclics. The issue of side effects depends on each patient's situation and symptoms. However, discussion of the relative value of these 2 classes of antidepressants should not obscure the fact that drug treatment, especially in general practice, is not necessarily always appropriate or sufficient.
Joanna Moncrieff BMedSci, MBBS Institute of Psychiatry, London, UK

1 Anderson IM, Tomenson BM. Treatment discontinuation with selective serotonin reuptake inhibitors compared with tricyclic antidepressants: a meta-analysis. BMJ 1995;310:1433-8.

2 The treatment of depression in primary care. Effective Health Care 1993;5:1-12.
Tone treatment of depression in prim

3 Song F, Freemantle N, Sheldon TA, et al. Selective serotonin reuptake inhibitors: a metaanalysis of efficacy and acceptability. $B M J$ 1993;306:683-7.

4 Anderson IM, Tomenson BM. The efficacy of selective serotonin re-uptake inhibitors in depression: a meta-analysis of studies against tricyclic antidepressants. J Psychopharmacol 1994;8:238-49.

5 Donoghue J, Tylee A, Wildgust H. Cross sectional database analysis of antidepressant prescribing in general practice in the United Kingdom. BMJ 1996;313:861-2. 